\title{
Flow cytometric examination of apoptotic effect on brain tissue in postnatal period created by intrauterine oxcarbazepine and gabapentin exposure
}

\author{
Erisgin $\mathrm{Z}^{1}$, Tekelioglu $\mathrm{Y}^{2}$ \\ Giresun University, Medical Faculty, Department of Histology and Embryology, Giresun, Turkey. \\ zerisgin@hotmail.com
}

\begin{abstract}
OBJECTIVE: For epileptics, pregnancy contains the balance between no seizure period and antiepileptic use having the least teratogenicity risk. The purpose is to analyse with flow cytometry the apoptotic effects on postnatal brain tissue caused by prenatal use of second generation antiepileptics oxcarbazepine (OXC) and gabapentin (GBP) having different effect mechanisms.

METHOD: 30 ( $n=5$ each group) Wistar albino male rats (45-days-old) are used. First 3 groups are exposed to OXC (100 mg/kg/day), GBP (50 mg/kg/day), and saline, respectively on the $1 \mathrm{st}-5$ th prenatal days (preimplantation-implantation period) while the second 3 groups are exposed to the same substances on the 6th-15th prenatal days (organogenesis), respectively. After sacrifice, brain tissue samples were made into suspension with mechanic and enzymatic digestion and examined with flow cytometry.

RESULTS: While apoptosis rate appeared high in rats exposed to OXC on the 1 st-5th $(p<0.001)$ and 6th-15th days $(p<0.001)$, no significant difference occurred for GBP $(p=0.004 ; p=0.012)$ and saline $(p=0.012)$. Considering time effect in three treatment groups, while difference was not significant for PSS and GBP groups $(p=0.847$ and $p=$ $0.934)$, apoptosis rate was significantly high for OXC on the 6th-15th days compared to the 1 st -5 th days $(p<0.001)$. CONCLUSION: It is observed that the use of OXC causes neurotoxicity during preimplantation, implantation and, especially, organogenesis period (neurogenesis) whereas GBP does not (Fig. 3, Ref. 32). Text in PDF www.elis.sk. KEYWORDS: apoptosis, flow cytometry, gabapentin, oxcarbazepine, pregnancy.
\end{abstract}

\section{Introduction}

Epilepsy, the existence of which is mentioned in Assyria-Babel writings dated back to three thousand years ago, still holds many mysteries (Engel and Pedley, 2008). Today, epilepsy treatment can only be made in order to eliminate its symptoms, and it becomes complex from pregnancy to breast-feeding processes for women who are in reproduction period (Crawfort, 2005). There are one million epileptics in the USA and 18 million in the world who are in reproduction period; also, $0.3-0.7 \%$ of pregnant women are epileptics (Thomas et al, 2009; Kulaga et al, 2011; Patel and Pennell, 2016). Although research shows that the use of certain antiepileptic drugs (AEDs) during pregnancy period cause teratogenicity, the use of these drugs become compulsory against epileptic attacks in order to protect mother and child health (Haurser, 2011). As a result of the clinical, epidemiological and experimental studies focused

${ }^{1}$ Giresun University, Medical Faculty, Department of Histology and Embryology, Giresun, Turkey, and ${ }^{2}$ Karadeniz Technical University, Medical Faculty, Department of Histology and Embryology, Trabzon, Turkey

Address for correspondence: Z. Erisgin, Giresun University, Medical Faculty, Deparment of Histology and Embryology, 28200, Giresun, Turkey. Phone: +90.454 .3103010$

Acknowledgements: Giresun University's Scientific Research Project Office supported this project (Project number: SAGBAP- A-200515-24). on the use of AEDs, and especially on the use of multiple drugs, during prenatal period, it is shown that their use results in various negative effects during childbirth (congenital malformation, low apgar score, low birth weight etc.) and postpartum period (neurocognitive problems) (Bogdan et al, 2012; Pennell et al, 2012; Aberg et al, 2013; Velez-RuizMeador, 2015). Today, it is known that especially drugs like valproic acid, first-generation AED, cause neural tube defects, cleft palate and cleft lip (Bogdan et al, 2012, Hernandez-Diaz et al. 2012). Although, the second-generation AEDs, which was defined to have both less side effects in clinical use and less possible teratogenicity, has been put to use, further studies raise consequencial questions about their use during pregnancy (Hill et al, 2010; Bogdan et al, 2012; William et al, 2012).

Oxcarbazepine (OXC), anticonvulsant from the second generation of drugs, shows its effect through blocking voltage-gated sodium channels. Besides, it enhances potassium transmission and glutamatergic transmission, and regulates the functions of calcium channels (Shorvon, 2000; Donner ve Snead, 2006).

Gabapentine (GBP) shows similarity with GABA and while GABA can not pass through blood-brain barrier, GBP can easily pass through it. It shows anticonvulsant effect through activating ion channels or through GABA secretion in nonsynaptic environment. It clings to alpha-2-delta subunit of L-type calcium channels and decreases the secretion of monoamine (McLean, 1995; Oka et al, 2003). 
107-111

Even though the reasons of teratogenicity caused by AEDs are attributed to drug-based folate deficit, the changes in endogenous bioelectric mechanisms and apoptosis etc.; congenital malformation mechanisms have not been clearly revealed yet. Besides, the possible cause of the negative effects during postnatal period and the relationship between AED use and neurotoxicity are not clear (Hernandez-Diaz and Levin, 2014). In this study, by using flow cytometry method, we tried to reveal the apoptotic effects of $\mathrm{OXC}$ and GBP exposition on brain tissue during preimplantationimplantation and neurogenesis processes.

\section{Material and method}

In this research, 30 Wistar albino (45-days-old) male rats obtained from 18 pregnant Wistar albino rats (10-12 weeks, 180200 g. Ondokuz Mayis University Animal Research Centre) were used. Female rats which were preserved under standard room conditions $\left(20 \pm 2{ }^{\circ} \mathrm{C}\right.$, on a 12: 12 hour light/dark cycle) were kept in the same place with male rats for one night; the females in whom plaques were observed on the next day were regarded as pregnant and the test procedure was applied. Eighteen pregnant rats were distributed into 6 groups. The first 3 groups were given OXC (100 mg/kg/day), GBP (50 mg/kg/day), saline (1.5 $\mathrm{ml})$, respectively on the $1 \mathrm{st}-5$ th days; and the second 3 groups were given OXC (100 mg/kg/day), GBP (50 mg/kg/day), saline $(1.5 \mathrm{ml})$, respectively and via gavage, on the 6 th -15 th days. Drug application periods were determined to take place before neurogenesis and to be enclosing the neurogenesis period (Ikonomidoua and Turski, 2007, Ikonomidoua et al, 2007). Choosing 5 rats from each group, 30 newborn male rats (45-days-old, $n=5$ per group) were used in total. Cardiac perfusion was made on male offspring rats after anaesthesia had been provided with ketamine $(70 \mathrm{mg} / \mathrm{kg})$ and xylazine $(0.5 \mathrm{mg} / \mathrm{kg})$. Their brain tissues were taken out and put into formalin. Later, brain tissue samples were made into suspension in PBS buffer with mechanic and enzymatic digestion and filtrated with DNA match. The tissue samples which were washed 2 times after being centrifuged under $1200 \mathrm{rpm}$ with $1 \mathrm{ml}$ PBS, were added $1.5 \mathrm{ml}$ bounding buffer and divided into $500 \mu$ eppendorfs. Samples in volume of $100 \mu$ l were taken from this solution and incubated under room temperature for 20 min with $5 \mu$ Annexin V and $5 \mu 17$ ADD (Apoptosis Detection Kit, BD Pharmingen). Then, $100 \mu$ l bounding buffer was added and analyses were made with BD Accuri C6® flow cytometry device (Fig. 1).
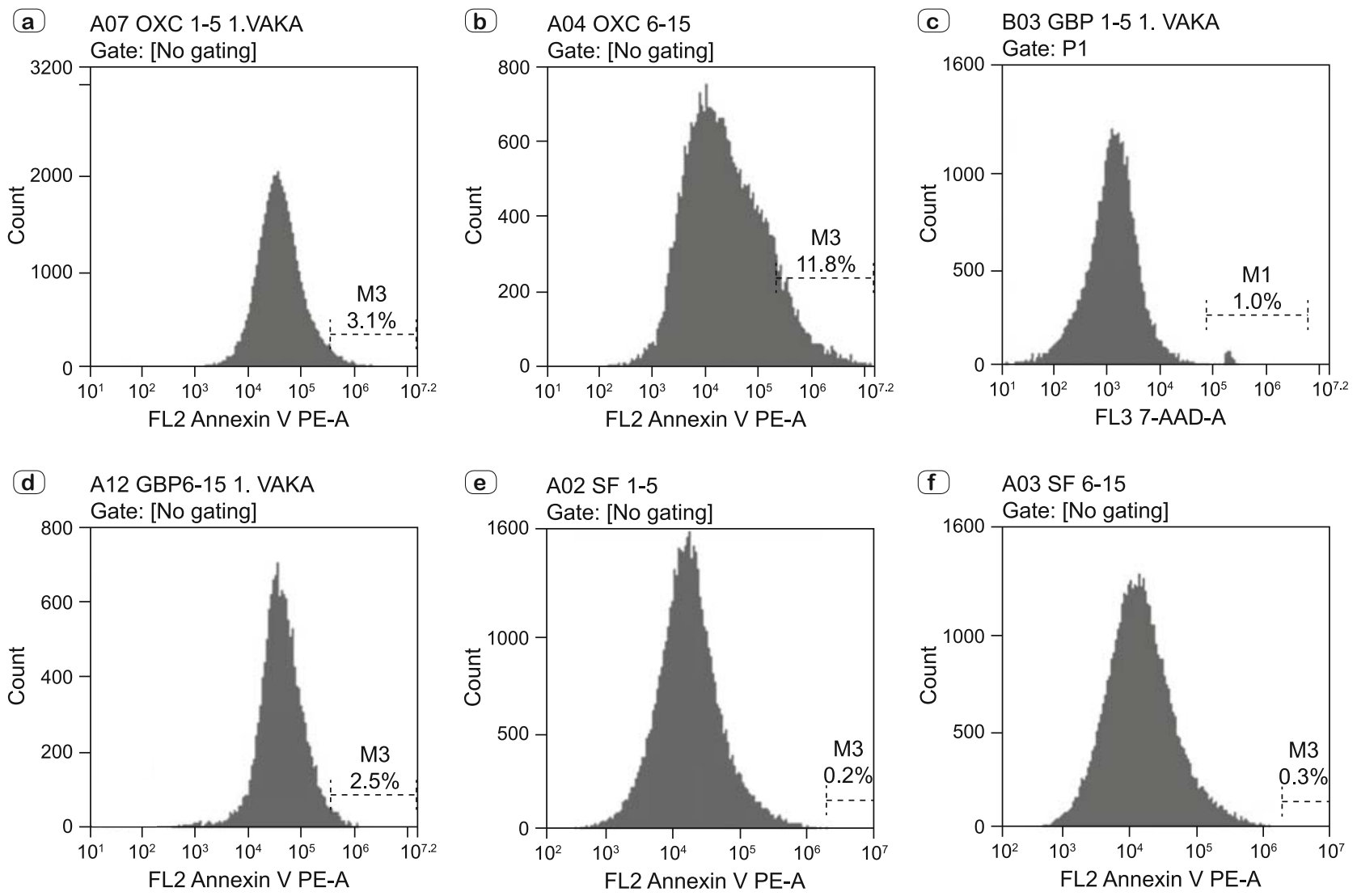

Fig. 1. Flow cytometry histogram samples of all groups showing Annexin V apoptosis (\%) values, a) OXC (1st-5th days), b) OXC (6th-15th days), c) GBP (1st-5th days), d) GBP (6th-15th days), e) Control (1st-5th days), f) Control (6 th-15th days). 


\section{Results}

Statistics

SPSS 13.0 program was used in the data analysis of this study. Normal distribution according to treatment groups and time groups was determined with Shapiro-Wilk test. p value over 0.05 was accepted as compliance with normal distribution. The data of all subgroups are found to be complying with normal distribution. Hence, the effect of two independent and categorical variables (treatment groups and time groups) on cerebral death was determined with Two-Way Anova test. In Two-way anova test, type 1 error was kept low and p value below 0.001 was accepted as a statistical significance level. The differences between groups are determined with the least significant difference method.

In the group administered with $\mathrm{OXC}$ on the $1 \mathrm{st}-5$ th prenatal days, apoptosis rate is found to be statistically significantly higher than in the groups to which PSS ( $p<0.001)$ and GBP $(p<0.001)$ were applied at the same time. However, no significant difference is seen between GBP and PSS groups $(\mathrm{p}=0.004)$ (Fig. 2).

In the group administered with $\mathrm{OXC}$ on the 6 th-15th prenatal days, apoptosis rate is found to be statistically significantly higher

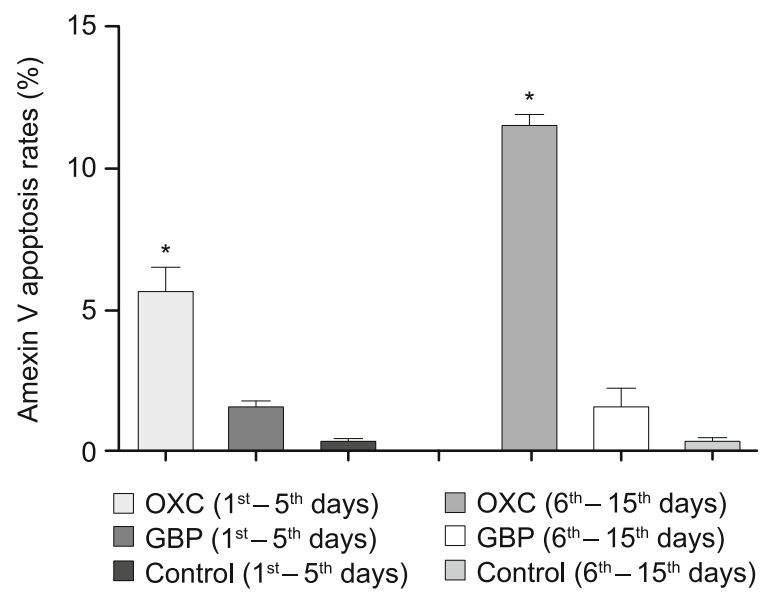

Fig. 2. The comparison of Annexin $\mathrm{V}$ apoptosis rates (\%) of all groups.

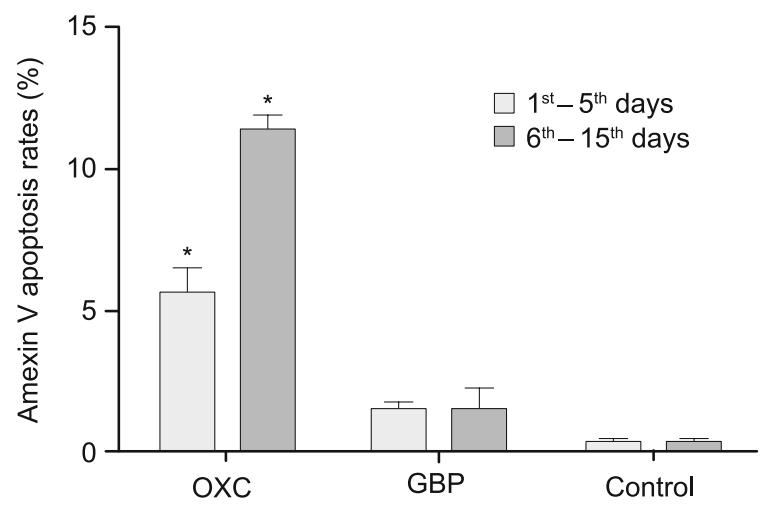

Fig. 3. The comparison of Annexin V apoptosis rates (\%) of the same drugs per treatment period. than in the groups to which PSS $(\mathrm{p}<0.001)$ and GBP $(\mathrm{p}<0.001)$ were applied at the same time. However, no significant difference is seen between GBP and PSS groups ( $=0.012$ ) (Fig. 2).

When each of these three treatment groups were examined among themselves for time effect, the difference between PSS and GBP groups is not significant $(\mathrm{p}=0.847$ and $\mathrm{p}=0.934)$. Nevertheless, in OXC group, apoptosis rate on the 6th-15th days is found to be statistically significantly higher than on the 1st-5th days $(\mathrm{p}<0.001)$ (Fig. 3).

\section{Discussion}

In our study, it is shown that OXC exposition during prenatal period may have neurotoxic effect whereas GBP does not have such an effect.

The most important problem faced by epileptic women during pregnancy is the formation of congenital malformation due to AED use. Though many studies attract notice to congenital malformations, it is revealed with the recent studies that various possible disorders or insufficiencies can emerge in the postnatal period, if not with congenital malformation. However, the formation mechanisms of congenital malformation and negative effects during postnatal period are still unknown (Patel and Pennell, 2016).

Although the amount of unknown facts about the relation between prenatal AED use and teratogenicity is large, there are many hypotheses which are related to the formation of teratogenicity due to AED use put forward by Manent et al, 2007, Etemad et al (2012), Kluger and Meador (2012), Hernandez Diaz and Levin (2014). These also include low folic acid level, change in the DNA of developing cell, apoptosis induction due to oxidative stress, inhibition in cell division, the effects of GABA and neurotransmitters such as neuron migration, and changes in the endogenous bioelectrical mechanism.

There are few experimental animal researches made on OCX. As a result of the study made on rats, Tecome (1999) reported that teratogenicity was observed from $250 \mathrm{mg} / \mathrm{kg} /$ day to $500 \mathrm{mg} / \mathrm{kg} /$ day and that there was also a delay in postnatal development. In the study made on mice, Bennett et al (1996) revealed that $1100 \mathrm{mg} / \mathrm{kg} /$ day OXC application on the 6th-18th days of pregnancy increases the rate of malformation. In the study made by Gurgen et al (2012), it was shown that in female rats administered with a similar dosage $(100 \mathrm{mg} / \mathrm{kg})$ for 3 months, there were negative effects for extracellular matrix proteins which play a role in embryo implantation.

Ambrósio et al (2000) showed that OXC use on rat hippocampal neuron culture creates neurotoxicity causing apoptosis. In the study made by Pavone and Cardile (2003) on glia cells, which are one the most important factors in neurogenesis, it was revealed that OXC stress induction shows an increase. In the cell culture study of Araujo et al (2004) made with embryonal hippocampus neurons on the 18-19th days of embryonal period, degeneration, increase in oxygen radicals, and decrease in intracellular ATP level and mitochondrial membrane potential were detected in the cells exposed to $300 \mu \mathrm{M}$ OXC. In their experimental epilepsy model made on mice, Agarwal et al (2011) argued that it did not cause any change in cognitive functions and oxidative stress parameters. 
107-111

Although there are studies which suggest that OXC causes MCA (major congenital malformation), there are also studies which report that the frequency of occurred congenital malformations is the same as in normal population.

Friis et al (1993) explored 3 aborted fetuses from 12 pregnancy cases in which OXC was used; Lassiter et al (2004) discovered cleft palate, fascial dimorphism, oligodactyly (three-fingers), head and body disproportionality, bladder anomalies in 5 babies of 75 pregnant women on whom monotherapy was applied. Among the data of 248 pregnant women who used OXC in monotherapy, Montouris (2005) reported that malformation prevalence was 2.4 $\%(6 / 248)$ for those who had monotherapy. Lastly, according to the study made in 1996-2000 by Sabers et al (2004), ventricular septal defect (VSD) was observed in 2 of 37 pregnancies inn which OXC was used.

In a prospective study made on 5 women who used OXC, Kinay et al (2008) could not detect congenital malformation in newborns except for seizure increase in pregnant women. Besides, Meischenguiser et al (2004) could not observe MCA among 35 pregnancy cases which used OXC in monotherapy. Eisenschenk (2006) reported that MCA and postnatal negative effect were not seen in 2 cases in which OXC was used (OXC dosage was increased up to $1050 \mathrm{mg} / \mathrm{kg}$ in the case of one of the pregnants) and which were followed during their pregnancies. Rabinowicz et al (2002) did not observe any congenital malformation in babies of 25 pregnant women who used OXC in monotherapy. In the research made on 837,795 live births by Nielsen and Hviid (2011) in 1996-2008, it was stated that MCA was observed in 11 (2.8\%) of 393 newborns who were exposed to OXC. According to this, it was shown that teratogenicity risk due to monotherapeutic use of OXC during pregnancy is the same as in normal population.

Although the use of OXC during pregnancy seems safe as a result of the studies made with limited cases, there are still many unknown points. Especially, the effects of OXC exposition during pregnancy on brain and its possible effects in postnatal period are still unknown. There are only a few studies which are similar to our study and the answer to this problem is yet to be discovered.

In animal studies made with GBP, Prakash et al (2008) applied GBP on mice as 4 different doses in the first and middle trimesters of pregnancy, and the highest resorption was seen in the first trimester and with the biggest dose application. Afshar et al (2009) applied intraperitoneal (i.p.) GBP in $25 \mathrm{mg} / \mathrm{kg}$ and $50 \mathrm{mg} / \mathrm{kg}$ doses covering two trimesters; this study corresponds with our study since fetal resorption was also seen in our study with similar dosage and application times. As it can also be seen in animal studies, GBP can cause substantial fetal resorption during the early stages of pregnancy. In the study made by Petrere and Anderson (2002), GBP was applied to rabbits, mice and ratsin the 2nd trimester of pregnancy. No side effect was seen up to $1500 \mathrm{mg} / \mathrm{kg}$ in pregnant mice, up to $3000 \mathrm{mg} / \mathrm{kg}$ in pregnant rats, and up to $300 \mathrm{mg} / \mathrm{kg}$ in pregnant rabbits. Yet, abortions and decrease in body weight were seen in rabbits at a $1500 \mathrm{mg} / \mathrm{kg}$ dose.

In the epidemiological studies on GBP, Montouris (2003) observed that 6 of 51 pregnancies to which polytherapy had been applied resulted in abortion; 6 newborns had low birth weight, and 3 newborns were born with congenital anomaly. In the study made on 7 pregnants who used approximately $1,843 \mathrm{mg}$ GBP for hyperemesis gravidarum, Guttuso et al (2010) observed spinal cord malformation, specifically on those who started to use it at the eighth week, and hydronephrosis, specifically on those who started to use it at the ninth week of pregnancy. Morrow et al (2006) reported that among 2,598 pregnancies, only 1 of 35 GBP monotherapeutic pregnant users had a ventricular septal defect. In a case report, Carrasco et al (2015) stated a GBP withdrawal syndrome in a baby girl who was exposed to GBP during her prenatal period. Guttuso et al (2014), Veiby et al (2014) and Fujii et al (2013) pointed out that prenatal GBP use can cause teratogenicity as much as in normal population. In homology modelling study, Piplani et al. remarked that there can be a relation between human placental cadherin protein and teratogenic effects of AEDs also linked to teratogenicity showing that GBP has high affinity towards cadherin.

Beside epileptic treatment, GBP is also used in cases such as restless leg syndrome, neuropathic pain, and hyperemesis gravidarum. Although it is shown with few studies that it causes teratogenicity, it is proven that its teratogenicity rate is seen to be the same as in normal population. However, the effects of prenatal GBP use on brain and postnatal period cognitive and other skills are still unknown. In our study, it is shown that the level of apoptosis during preimplantation and implantation period caused by GBP is the same as in control group, and that its use during pregnancy is rather safer.

\section{Conclusion}

Independently of epileptic seizures and maternal genetic effects, it is revealed in our study that OCX from second generation AEDs causes apoptosis in the brain, whereas GBP does not show such neurotoxicity. Although in epidemiological studies, attention is paid to congenital malformation; it is shown in our and other experimental studies that even though AEDs do not cause congenital malformation, they can lead to various negative effects on tissue surface. Furthermore, this study gave rise to a new question as to how the apoptotic effect of OXC on brain acts upon cognitive and other skills in postnatal period. Besides, this study also partly reveals that GBP is a most preferable drug during pregnancy period.

\section{References}

1. Agarwal NB, Agarwal NK, Mediratta PK, Sharma KK. Effect of lamotrigine, oxcarbazepine and topiramate on cognitive functions and oxidative stress in PTZ-kindled mice. Seizure 2011; 20 (3): 257-262.

2. Kluger BM, Meador KJ. Teratogenicity of Antiepileptic Medications. Semin Neurol 2008; 28 (3): 328-335.

3. Wlodarczyk BJ, Palacios AM, George TM, Finnell RH. Antiepileptic Drugs and Pregnancy Outcomes. Am J MedGenet A 2012; 158 (8): 2071-2090.

4. Carrasco M, Rao SC, Bearer CF, Sundararajan S. Neonatal Gabapentin Withdrawal Syndrome. Pediatr Neurol 2015; 53 (5): 445-447. 
5. Crawfort P. Best Practice Guidelines for the management of women with epilepsy. Epilepsia 2005; 46 (9): 117-124.

6. Hill DS, Wlodarczyk BJ, Palacios AM, Finnell RH. Teratogenic effects of antiepileptic drugs. Expert Rev Neurother 2010; 10 (6): 943-959.

7. Donner EJ, Snead OC. III. New Generation Anticonvulsants for the Treatment of Epilepsy in Children. NeuroRx 2006; 3 (2): 170-180.

8. Aberg E, Holst S, Neagu A, Ögren SO, Lavebratt C. Prenatal Exposure to Carbamazepine Reduces Hippocampa and Cortical Neuronal Cell Population in New-Born and Young Mice with out Detectable Effects on Learning And Memory. PLoSOne 2013; 8 (11): e80497.

9. Engel J, Pedley TA. What's epilepsy? In: Ergel J, Pedley TA, editors. Epilpesy A Comprehensive Textbook. Volume 1. USA; Wolters Kluwer/ Lippincott Williams \& Wilkins, 2008: 1.

10. Fujii H, Goel A, Bernard N, Pistelli A, Yates LM, Stephens S, Han JY, Matsui D, Etwell F, Einarson TR, Koren G, Einarson A. Pregnancy outcomes following gabapentin use: results of a prospective comparative cohort study. Neurology 2013; 23; 80 (17): 1565-1570.

11. Gürgen SG, Erdoğan D, Coşkun ZK, Cansu A. The effect of valproic acid and oxcarbazepine on the distribution of adhesion molecules in embryo implantation. Toxicology 2012; 26; 292 (2-3): 71-77.

12. Guttuso T Jr, Shaman M, Thornburg LL. Potential maternal symptomatic benefit of gabapentin and review of its safety in pregnancy. Eur J Obstet Gynecol Reprod Biol 2014; 181: 280-283.

13. Hauser WA. Antiepilepticdrugs in pregnancy: refinement of risk estimates. The Lancet Neurol 2011; 10 (7): 592-593.

14. Hernández-Díaz S, Smith CR, Shen A, Mittendorf R, Hauser WA, Yerby M, Holmes LB, North American AED Pregnancy Registry. Comparative safety of antiepileptic drugs during pregnancy. Neurology 2012, 22; 78 (21): 1692-1699.

15. Ikonomidoua C, Scheerb I, Wilhelme T, Juenglingd FD, Titzee K, Stoverc B, Lehmkuhlf U, Kochg S, Kassubek J. Brain morphology alterations in the basal ganglia and the hypothalamus following prenatal exposure to antiepilepticdrugs. J Eur Pediat Neurol 2007; 11: 297-301.

16. Ikonomidoua C, Turski L. Antiepileptic drugs and brain development. Epilepsy Res 2010; 88 (1): 11-22.

17. Kulaga S, Sheehy O, Zargarzadeh AH, Moussally K, Berard A. Antiepileptic drug use during pregnancy: Perinatal outcomes. Seizure 2011; 20: 667-672.

18. Etemad L, Moshiri M, Moallem SA. Epilepsy drugs and effects on fetal development: Potential mechanisms. J Res Med Sci 2012; 17 (9): 876-881.
19. Manent JB, Jorquera I, Mazzucchelli I, Depaulis A, Perucca E, Ben-Ari Y, Represa A. Epilepsia. Fetal exposure to GABA-acting antiepileptic drugs generates hippocampal and cortical dysplasias 2007; 48 (4): 684-693.

20. Manent JB, Represa A. Neurotransmitters and brain maturation: early paracrine actions of GABA and glutamate modulate neuronal migration. Neuroscientist 2007; 13 (3): 268-279.

21. McLean MJ. Gabapentin in the Management of Convulsive Disorders. Epilepsia1999; 40 (6): 39-50.

22. Velez-Ruiz NJ, Meador KJ. Neurodevelopmental Effects of Fetal Antiepileptic Drug Exposure. Drug Saf 2015; 38 (3): 271-278.

23. Oka M, Itoh Y, Wada M, Yamamoto A, Fujita T. Gabapentinblocks L typeand $\mathrm{P} / \mathrm{Q}$-type $\mathrm{Ca} 2+$ channels involved in depolarization- stimulated nitric oxide synthase activity in primary cultures of neurons from Mouse cerebral cortex. Pharm Res 2003; 20: 897-899.

24. Pavone A, Cardile V. An in vitro study of new antiepileptic drugs and astrocytes. Epilepsia 2003; 44; 110: 34-39.

25. Pennell PB, Klein AM, Browning N, Baker GA, Clayton-Smith J, Kalayjian LA, Liporace JD, Privitera M, Crawford T, Loring DW, Meador KJ, NEAD StudyGroup. Differential effects of antiepileptic drugs on neonatal outcomes. Epilepsy Behav 2012; 24 (4): 449-456.

26. Piplani S, Saini V, Niraj RR, Pushp A, Kumar A. Homology modelling and molecular docking studies of human placental cadherin protein for its role in teratogenic effects of anti-epileptic drugs. Comput Biol Chem 2016; 60: 1-8.

27. Shorvon S. Oxcarbazepine: a review. Seizure 2000; 9: 75-79.

28. Patel SI, Pennell PB. Management of epilepsyduringpregnancy: an update. Ther Adv Neurol Disord 2016; 9 (2): 118-129.

29. Hernández-Díaz S, Levin M. Anticonvulsants Teratogenic Mechanism Involves Alteration of Bioelectrically-controlled Processes in the Embryo. A hypothesis. Reprod Toxicol 2014; 47: 111-114.

30. Thomas SV, Sindhu K, Ajaykumar B, Devi PB, Sujamol J. Maternalandobstetricoutcome of womenwithepilepsy. Seizure 2009; 18: 163-166.

31. Veiby G, Daltveit AK, Engelsen BA, Gilhus NE. Fetal growth restriction and birth defects with newer and older antiepileptic drugs during pregnancy. J Neurol 2014; 261 (3): 579-588.

32. BoboWV, Davis RL, Toh SD, Li DK, Andrade SE, Cheetham TC, Pawloski P, Dublin S, Pinheiro S, Hammad T, Scott PE, Epstein RA, Jr, Arbogast PG, Morrow JA, Dudley JA, Lawrence JM, Avalos LA, Cooper WO. Trends in the use of antiepilepticdrugs (AEDs) among pregnant women in the U.S., 2001-2007: a Medication Exposure in Pregnancy Risk Evaluation Program (MEPREP) study. Paediatr Perinat Epidemiol 2012; 26 (6): 578-588. 